\title{
Delays and routes to diagnosis of neuroendocrine tumours
}

\author{
Ron Basuroy ${ }^{1}$, Catherine Bouvier ${ }^{2}$, John Keith Ramage ${ }^{3}$, Maia Sissons ${ }^{2}$ and Raj Srirajaskanthan ${ }^{3,4^{*}}$ (I)
}

\begin{abstract}
Background: Neuroendocrine tumours are uncommon tumours; there is often a long period between the onset of symptoms and diagnosis. This study aims to address the symptoms prior to diagnosis of people with known neuroendocrine tumours and also the involvement of healthcare providers prior to the diagnosis.

Methods: A web based survey was designed to cover two broad areas of patient symptoms and healthcare interactions prior to diagnosis. This was tested and adapted by patient and clinician input prior to distribution via Survey Monkey.

Results: The results demonstrated a median time from first symptom to diagnosis of 53.8 months. The most frequent initial symptoms were of pain, change in bowel habit and fatigue. $31 \%$ of respondents noted weight loss prior to diagnosis. 80\% of respondents visited their GP regarding the symptoms a median of 11 times. 58\% of respondents were referred to secondary care where they were seen a median 3 times. 30\% presented acutely to A\&E and this led to their diagnosis.

Conclusion: In conclusion, there is a long time from onset of symptoms to diagnosis in all types of NETs. This is despite many respondents having alarm symptoms at diagnosis. Further education and awareness regarding malignancy may help with earlier diagnosis.
\end{abstract}

Keywords: Symptoms, Neuroendocrine tumour, Gastrointestinal, Lung, Delay, Diagnosis and pancreas

\section{Background}

Neuroendocrine tumours (NETs) are rising in incidence and prevalence [1]. These tumours can arise in most organs of the body and can present with a multitude of symptoms [2]. They are regarded as rare cancers with a reported incidence of 5-7 per 100,000 population per year and estimated prevalence of 35 per 100,000 [1]. Symptoms leading to diagnosis are varied and dependent in part on the primary site of the tumour and also whether the tumours are functional in nature and causing a clinical syndrome such as carcinoid syndrome [3]. The majority of tumours are non-functional and consequently the presentation may be incidental or related to mass effect of tumour or metastatic disease [4]. The functional tumours can cause clinical syndromes; the

\footnotetext{
* Correspondence: r.srirajaskanthan@nhs.net

${ }^{3}$ ENETS Centre of Excellence, Neuroendocrine Tumour Unit, Kings College Hospital, London, UK

${ }^{4}$ Department of Gastroenterology, Kings College Hospital, London SE5 9RS, UK

Full list of author information is available at the end of the article
}

most commonly recognised is carcinoid syndrome, though other symptoms/syndromes can occur, for example Zollinger Ellison syndrome in gastrinoma or Werner Morrison syndrome in VIP secreting tumours [5].

Anecdotally there is thought to be a delay in diagnosis due to the nature of the symptoms and patients being given an incorrect initial diagnosis [6, 7]. The duration of a delay in diagnosis is unclear but there are reports in the literature of delays in years prior to diagnosis. $\mathrm{Pa}$ tients commonly have diagnoses confused with other conditions such as dyspepsia or irritable bowel syndrome [8]. The incidence of misdiagnosis is unclear and the duration to diagnosis is also not well established.

There is minimal literature on the presenting symptoms of patients with NETs and the duration of symptoms prior to diagnosis [9]. It is also not clear how long symptomatic NET patients are investigated and managed before diagnosis by healthcare practitioners in both primary and secondary care, and whether this contributes to an avoidable delay.

C The Author(s). 2018 Open Access This article is distributed under the terms of the Creative Commons Attribution 4.0 International License (http://creativecommons.org/licenses/by/4.0/), which permits unrestricted use, distribution, and reproduction in any medium, provided you give appropriate credit to the original author(s) and the source, provide a link to the Creative Commons license, and indicate if changes were made. The Creative Commons Public Domain Dedication waiver (http://creativecommons.org/publicdomain/zero/1.0/) applies to the data made available in this article, unless otherwise stated. 
The aims of this study were to understand the symptoms patients experience prior to diagnosis, the duration of these symptoms and their interaction with healthcare services prior to diagnosis. The survey was open to all patients with NETs to enable an overall view of symptoms prior to diagnosis and also assess whether time to diagnosis was different between different tumour sites.

\section{Methods}

In collaboration with the NET patient foundation (NPF) we designed a web based survey. The NPF is a UK based neuroendocrine patient organization. The survey was created on SurveyMonkey and covered two broad areas of patient symptoms and healthcare interactions prior to diagnosis. No personal data questions, including contact details, were incorporated into the survey. Using the HRA decision aids tool an online form was completed, it confirmed that NHS REC approval was not required. The survey was entirely voluntary, and respondents were fully informed on the website about why the survey was being done.

We employed free text open questions at the start of the survey to enable a broad depth of data capture. Mandatory questions enabled us to filter responses to relevant sections and hence avoid respondent fatigue. Questions were developed using a multiple choice options, a 5 point scale or free text. The questions focusing on timeline and duration of symptoms were calculated using the baseline data of patients current age and the data at which they completed the survey.

The survey contained 130 questions and took around $30 \mathrm{~min}$ to complete. The set of questions were designed by the authors and clinical team at Kings College hospital Neuroendocrine Tumour Unit. The survey was then tested and adapted by trialing with patients and clinicians. The groups of questions included first and most troublesome symptoms, weight and appetite change, alarm signs,
GP and hospital interactions, and diagnosis. Respondents were asked about change in weight and with weight loss of $4.5 \mathrm{~kg}$ or more categorized as relevant weight loss.

A link to the survey was posted on the NPF website and via their regular newsletter and Twitter update. In addition, the survey was distributed via clinical nurse specialists from NET centers around England using business cards containing the URL to access the survey. Following obtaining 300 responses the survey was closed, this was to ensure that the data would be sufficiently robust to describe patterns in symptoms and healthcare interactions. Data coding and analysis was performed with Microsoft ${ }^{\circ}$ Excel $^{\circ}$ for Mac (2011). Free text response data was searched and categorised with key word searches. Descriptive statistics were used given the lack of counterfactual.

\section{Results}

There was a total of 303 responses of which 229 completed the whole survey (75.6\%). The mean time to complete the survey was $34 \mathrm{~min}$. The majority of respondents were female patients (205/303, 67.65), including those who completed the whole survey $(154 / 229,67.2 \%)$. $76 \%$ of respondents $(231 / 303)$ completed the ethnicity question (grouped as per UK Office for National Statistics) with the overwhelming majority describing themselves as of white ethnicity (94\%). The mean age of respondents completing the survey was 55.7 years old with the mean ages for female and male respondents of 53.3 and 60.8 years old respectively. Respondents completed the survey on average 4 years after their initial NET diagnosis (mean age at diagnosis 51.6 years old). The interval between diagnosis and survey responses may lead to recall and reporting biases. The mean age at diagnosis was 51.6 years old for all respondents. Table 1. illustrates the number of respondents to the survey by primary site and also the average age of diagnosis.

Table 1 This demonstrates the mean age at diagnosis of the respondents by primary site. In addition, identifying the \% of respondents over the age of 50 at time of first symptom

\begin{tabular}{|c|c|c|c|c|c|c|}
\hline Type of NET & No. & $\begin{array}{l}\text { Mean age at } \\
\text { Diagnosis (years) }\end{array}$ & $\begin{array}{l}\% \text { with symptoms } \\
\text { at diagnosis }\end{array}$ & $\begin{array}{l}\text { Mean duration 1st } \\
\text { symptom (range, months) }\end{array}$ & $\begin{array}{l}\text { Mean Age at start of } \\
\text { 1st symptom (years) }\end{array}$ & $\begin{array}{l}\% \text { aged over } 50 \text { at } \\
1 \text { st symptom }\end{array}$ \\
\hline Appendix & 14 & 44.2 & $71 \%$ & $46.8(2-180)$ & 41.7 & $29 \%$ \\
\hline Lung & 51 & 50.7 & $59 \%$ & $67.7(1.5-360)$ & 46.2 & $54 \%$ \\
\hline Not sure & 20 & 47.5 & $70 \%$ & $71.9(2-264)$ & 43.3 & $55 \%$ \\
\hline Ovary & 2 & 44.3 & $50 \%$ & $5.00(4-6)$ & 43.8 & $0 \%$ \\
\hline Pancreas & 64 & 49.2 & $73 \%$ & $39.1(0-240)$ & 46.6 & $42 \%$ \\
\hline Rectal & 5 & 45.4 & $60 \%$ & $41.1(1-120)$ & 42.0 & $60 \%$ \\
\hline Renal/Kidney & 1 & 48.0 & $100 \%$ & - & - & - \\
\hline Small Bowel & 99 & 55.2 & $83 \%$ & $60.1(0-300)$ & 50.8 & $69 \%$ \\
\hline Stomach/gastric & 14 & 55.1 & $71 \%$ & $38.5(1-144)$ & 53.0 & $71 \%$ \\
\hline Unknown Primary & 33 & 52.9 & $70 \%$ & $43.4(1.5-204)$ & 50.4 & $55 \%$ \\
\hline Total/(Mean) & 303 & $(51.6)$ & $(73 \%)$ & $(53.8)$ & $(48.1)$ & $(56 \%)$ \\
\hline
\end{tabular}


The mean duration of the first symptom prior to diagnosis for respondents was 53.8 months overall, 60.1 months for small bowel NETs (sbNETs), 39.1 months for pancreatic NETs (pNETs) and 67.7 months for lung NETs. The mean age at onset of first symptom was 48.1 years for all respondents and 50.8, 46.6 and 46.2 years for small bowel, pancreatic and lung NETs respectively. Over half of all respondents (56\%) were aged over 50 years old at the time of developing their first NET symptom.

\section{Symptoms prior to diagnosis}

$80 \%$ of respondents reported that they had symptoms prior to diagnosis (243/303). Most of these respondents reported that their symptoms led to the NET diagnosis $(73 \%, 221 / 303)$, in particular those with pNETs $(73 \%$, $47 / 64)$ and small bowel NETs $(83 \%, 82 / 99)$. Over half of respondents reported that their symptoms led to a scan $(124 / 221,56 \%)$ and a subsequent NET diagnosis. $66 \%$ of pNET respondents $(31 / 47)$ and $57 \%$ of sbNET respondents (47/82) had symptoms that led to a scan and diagnosis.

\section{First symptom}

$81 \%$ of symptomatic respondents $(180 / 243)$ described their first symptom in free text that was categorized into seven main areas; diarrhoea, pain, flushing, cough, wheeze, tiredness/fatigue and other. The majority of respondents described a single symptom $(70 \%, 126 / 180)$ while the remainder described two or more symptoms in free text from the seven main areas. The most frequently described first symptom prior to diagnosis was pain (33\%) followed by diarrhoea (22\%), flushing (17\%) and cough (10\%). Respondents with small bowel NETs described pain (36\%), flushing (26\%) and diarrhoea (24\%) as the most common first symptoms. Respondents with pancreatic NETs described pain (39\%), diarrhoea (26\%) and fatigue or tiredness $(26 \%)$ as the most common first symptoms. Respondents with lung NETs described cough (53\%), wheeze (17\%), pain $(11 \%)$ and diarrhoea (11\%) as the most common first symptoms. The symptoms appear related to the primary site for example abdominal pain being frequently reported with gastrointestinal NETs. Figure 1 . lists the primary symptoms commonly associated with the tumour site. Almost all

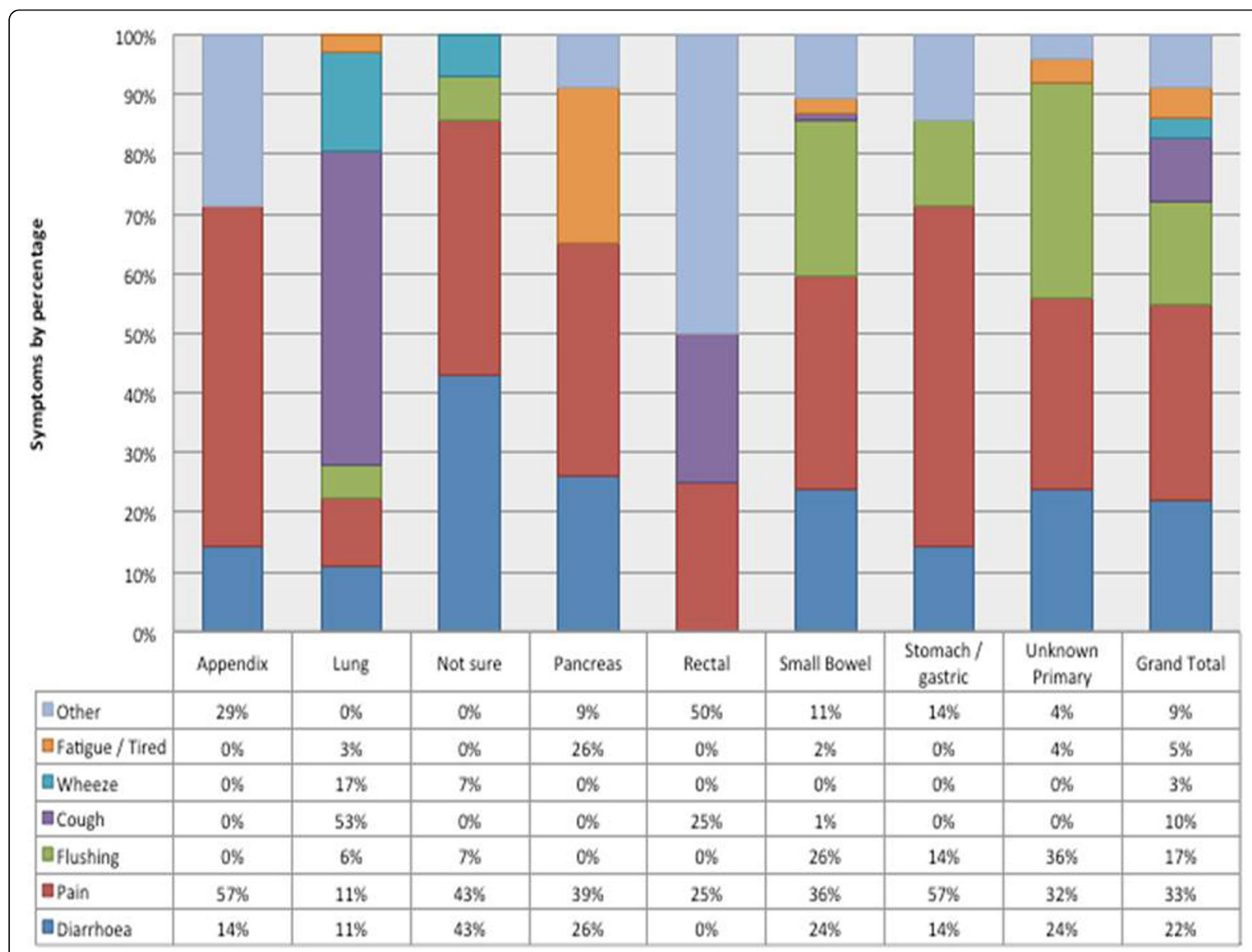

Fig. 1 Illustrates the frequency of the seven main primary symptoms reported by respondents dependent on the site of primary tumour 
respondents who reported symptoms prior to diagnosis $(99 \%, 240 / 243)$ graded the severity of their symptoms on a 5 -point scale (very mild, mild, moderate, severe, very severe). $63 \%$ of all those who responded reported their first symptom before diagnosis was severe or very severe (151/ 240). Table 2. describes the severity of the initial symptom based on tumour site.

\section{Other severe symptom}

Over half of all symptomatic respondents (133/243, $55 \%)$ reported in free text that they had a different more severe symptom prior to diagnosis from their initial symptom. 59\% of these respondents (78/133) described this additional more severe symptom in free text that was categorized into seven main areas; diarrhoea, pain, flushing, cough, wheeze, tiredness/fatigue and other. There was limited response data for NETs beyond those with pancreatic, small bowel and lung NETs. 78\% of all those who responded reported their severest symptom as severe or very severe (103/133). $80 \%$ of sbNET respondents graded their most severe symptom as severe or very severe compared with $90 \%$ of pNET and $60 \%$ of lung NET respondents.

\section{Weight and appetite change}

$42 \%(126 / 303)$ of respondents reported no change to weight prior to their diagnosis, $31 \%$ reported weight loss $(93 / 303)$ and $19 \%$ reported weight gain $(58 / 303)$. There were similar proportions of sbNET $(37 / 99,37 \%)$ and pNET $(19 / 64,30 \%)$ respondents reporting weight loss, while there was a lower proportion for lung NETs respondents $(10 / 51,20 \%)$.

$55 \%(168 / 303)$ of respondents reported no change to their appetite prior to diagnosis, 25\% reported appetite loss $(77 / 303)$ and $10 \%$ reported appetite gain $(31 / 303)$. There were similar proportions of sbNET (31/99, 31\%) and pNET $(14 / 64,22 \%)$ respondents reporting appetite loss, while there was a lower proportion for lung NETs respondents $(9 / 51,18 \%)$. However, the majority of sbNET, pNET and lung NET respondents reported no change to their appetite prior to diagnosis; $61 \%$ (60/99), $53 \%(34 / 64)$ and $65 \%(33 / 51)$ respectively. Table 3. describes the changes in weight and appetite in detail for respondents of each tumour site.
The mean weight change for sbNET and pNET respondents was a loss of -4.1 and $-0.4 \mathrm{~kg}$ respectively. $60 \%$ of sbNET and $45 \%$ of pNETs reported greater than $4.5 \mathrm{~kg}$ weight loss. Weight change was reported over a mean duration of 24 months for respondents with a similar duration for sbNETs (26 months) but a shorter duration for pNETs (15 months). Cohorts of respondents who also reported a loss of appetite (number, \%) had marked weight loss; $-9.8 \mathrm{~kg}$ overall $(77 / 303,25 \%)$, $11.7 \mathrm{~kg}$ sbNETs $(31 / 99,31 \%),-6.6 \mathrm{~kg}$ pNETs $(14 / 64$, $22 \%)$ and $-10.8 \mathrm{~kg}$ lung NETs $(9 / 51,18 \%)$.

\section{Abdominal and back pain}

$69 \%$ of respondents $(175 / 252$, excluding those with lung NETs) reported abdominal or back pain prior to diagnosis. Table 4, details the presence of abdominal and or back pain reported by respondents from different tumour sites. As expected 93\% of appendiceal NETs described pain, however, this was likely from the appendicitis that led to their presentation rather than the tumour. However, small bowel NET $(81 \%, 80 / 99)$ respondents reported pain more than pNET $(55 \%, 35 / 64)$ respondents prior to the diagnosis. sbNET respondents described the pain as starting in the periumbilical (26\%) or pelvic area (24\%) before becoming more generalized to the abdominal midline and lower abdomen (62\%) prior to diagnosis. pNET respondents described the pain as starting in the epigastric (39\%) or upper right abdomen area (10\%) before becoming more diffuse in it's location prior to diagnosis. There was no differentiating characteristic to the pain experienced by sbNET and pNET respondents, or association with other intestinal symptoms (bowel frequency, stool consistency, partial obstruction). The frequency of the pain was similar for both sbNETs and pNETs, occurring a few times a month or greater than once a week. sbNET respondents described a more severe pain profile than $\mathrm{pNET}$ respondents.

\section{Bowel symptoms}

Half of respondents (125/252, excluding lung NETs) reported problems with their bowels prior to diagnosis. The proportion experiencing bowel problems was greater for sbNETs $(64 \%, 63 / 99)$ than for pNETs

Table 2 Describes the severity of the primary symptom as reported by respondents from different primary sites

\begin{tabular}{|c|c|c|c|c|c|c|c|c|c|c|}
\hline Severity & Appendix & Lung & Not sure & Ovary & Pancreas & Rectal & Small Bowel & Stomach/gastric & Unknown Primary & Overall \\
\hline Very mild & $10 \%$ & $5 \%$ & $0 \%$ & $0 \%$ & $0 \%$ & $20 \%$ & $2 \%$ & $0 \%$ & $0 \%$ & $3 \%$ \\
\hline Mild & $20 \%$ & $11 \%$ & $0 \%$ & $0 \%$ & $12 \%$ & $20 \%$ & $5 \%$ & $22 \%$ & $13 \%$ & $9 \%$ \\
\hline Moderate & $30 \%$ & $26 \%$ & $33 \%$ & $0 \%$ & $24 \%$ & $60 \%$ & $24 \%$ & $22 \%$ & $22 \%$ & $25 \%$ \\
\hline Severe & $40 \%$ & $32 \%$ & $53 \%$ & $100 \%$ & $46 \%$ & $0 \%$ & $39 \%$ & $44 \%$ & $43 \%$ & $40 \%$ \\
\hline Very severe & $0 \%$ & $26 \%$ & $13 \%$ & $0 \%$ & $18 \%$ & $0 \%$ & $31 \%$ & $11 \%$ & $22 \%$ & $23 \%$ \\
\hline Responses & 10 & 38 & 15 & 2 & 50 & 5 & 88 & 9 & 23 & 240 \\
\hline
\end{tabular}


Table 3 This identifies the change in weight and appetite reported by respondents by primary site

\begin{tabular}{|c|c|c|c|c|c|c|c|c|c|}
\hline \multirow[b]{2}{*}{ Row Labels } & \multirow[b]{2}{*}{ Respondents } & \multicolumn{4}{|c|}{ Weight } & \multicolumn{4}{|l|}{ Appetite } \\
\hline & & Loss & Gain & No change & Unsure & Decrease & Increase & No change & Unsure \\
\hline Appendix & 14 & $21 \%$ & $14 \%$ & $36 \%$ & $29 \%$ & $21 \%$ & $7 \%$ & $50 \%$ & $21 \%$ \\
\hline Lung & 51 & $20 \%$ & $33 \%$ & $37 \%$ & $10 \%$ & $18 \%$ & $10 \%$ & $65 \%$ & $8 \%$ \\
\hline Not sure & 20 & $35 \%$ & $25 \%$ & $15 \%$ & $25 \%$ & $25 \%$ & $20 \%$ & $15 \%$ & $40 \%$ \\
\hline Ovary & 2 & $100 \%$ & $0 \%$ & $0 \%$ & $0 \%$ & $100 \%$ & $0 \%$ & $0 \%$ & $0 \%$ \\
\hline Pancreas & 64 & $30 \%$ & $22 \%$ & $44 \%$ & $5 \%$ & $22 \%$ & $20 \%$ & $53 \%$ & $5 \%$ \\
\hline Rectal & 5 & $0 \%$ & $40 \%$ & $60 \%$ & $0 \%$ & $0 \%$ & $20 \%$ & $80 \%$ & $0 \%$ \\
\hline Renal/Kidney & 1 & $0 \%$ & $0 \%$ & $100 \%$ & $0 \%$ & $0 \%$ & $100 \%$ & $0 \%$ & $0 \%$ \\
\hline Small Bowel & 99 & $37 \%$ & $15 \%$ & $42 \%$ & $5 \%$ & $31 \%$ & $3 \%$ & $61 \%$ & $5 \%$ \\
\hline Stomach/gastric & 14 & $36 \%$ & $7 \%$ & $57 \%$ & $0 \%$ & $29 \%$ & $0 \%$ & $57 \%$ & $14 \%$ \\
\hline Unknown Primary & 33 & $30 \%$ & $6 \%$ & $52 \%$ & $12 \%$ & $27 \%$ & $9 \%$ & $58 \%$ & $6 \%$ \\
\hline Overall & & $31 \%$ & $19 \%$ & $42 \%$ & $9 \%$ & $25 \%$ & $10 \%$ & $55 \%$ & $9 \%$ \\
\hline Respondents & 303 & 93 & 58 & 126 & 26 & 77 & 31 & 168 & 27 \\
\hline
\end{tabular}

The three most common primary sites are highlighted in yellow

$(36 \%, 23 / 64)$. Three quarters of respondents $(75 \%$, $62 / 83$ ) experienced problems with loose, mushy or watery stools prior to diagnosis. $46 \%$ of sbNET respondents $(21 / 46)$ described the problem with loose bowels as severe or very severe. $60 \%$ of small bowel NET patients reported that $3 / 4$ of their stools were loose prior to diagnosis. $66 \%$ of sbNET respondents $(57 / 87)$ reported some degree of urgency to open their bowels and 78\% (68/87) reported some degree of bloating.

\section{Other symptoms}

$67 \%$ of respondents $(95 / 141$, excluding those with lung NETs) reported flushing prior to diagnosis. Small bowel NET $(83 \%, 72 / 87)$ respondents reported flushing more than pNET $(43 \%, 23 / 54)$ respondents prior to the diagnosis. Almost a third of sbNET respondents described

Table 4 This table documents the incidence of abdominal pain and/ or as described by respondents dependent on the primary site of the tumour

\begin{tabular}{lllll}
\hline Row Labels & Respondents & Yes & No & Not sure /- \\
\hline Appendix & 14 & $93 \%$ & $0 \%$ & $7 \%$ \\
Not sure & 20 & $50 \%$ & $10 \%$ & $40 \%$ \\
Ovary & 2 & $50 \%$ & $50 \%$ & $0 \%$ \\
Pancreas & 64 & $55 \%$ & $39 \%$ & $6 \%$ \\
Rectal & 5 & $60 \%$ & $20 \%$ & $20 \%$ \\
Renal / Kidney & 1 & $0 \%$ & $0 \%$ & $100 \%$ \\
Small Bowel & 99 & $81 \%$ & $15 \%$ & $4 \%$ \\
Stomach / gastric & 14 & $71 \%$ & $21 \%$ & $7 \%$ \\
Unknown Primary & 33 & $70 \%$ & $21 \%$ & $9 \%$ \\
Overall & $100 \%$ & $69 \%$ & $21 \%$ & $9 \%$ \\
Respondents & 252 & 175 & 54 & 74 \\
\hline
\end{tabular}

the flushing as severe or very severe (31\%, 22/72). Alcohol and large meals were reported by sbNET respondents to make the flushing worse. $60 \%$ of respondents (84/141, excluding those with lung NETs) reported anxiety prior to diagnosis. Small bowel NET $(66 \%, 57 / 87)$ respondents reported anxiety more than pNET $(50 \%, 27 /$ 54) respondents prior to the diagnosis. A small proportion of sbNET respondents described the anxiety as severe or very severe $(16 \%, 9 / 57)$. Respondents reported nausea in $45 \%$ and vomiting in $36 \%$ of cases (65/146 and 52/146 respectively, excluding those with lung NETs) prior to diagnosis. $35 \%$ of respondents (49/139, excluding those with lung NETs) reported problems with breathing prior to diagnosis. The respondent data available limited further analysis of these symptoms.

\section{Accessing healthcare services and diagnosis}

The majority of respondents (80\%) reported that they saw their GP with symptoms prior to their NET diagnosis. Respondents reported they saw their GP over a mean period of 37 months and a mean of 11 interactions. There was no marked difference in the mean period and interactions in primary care for respondents. Table 5 . details the interaction of respondents with primary care. The duration of recurrent attendance to primary care implies that symptoms had not improved. It seems that initial incorrect diagnosis was given to patients based on the high number of respondents reporting a diagnosis of functional bowel syndrome, such as irritable bowel syndrome, or dyspepsia. Table 6. outlines the initial diagnosis given to respondents in primary or secondary care.

Over half of respondents $(58 \%, 122 / 210)$ reported that they first interacted with secondary care from a GP referral to a local hospital clinic. Almost a third of respondents $(31 \%, 66 / 210)$ reported that their first secondary 
Table $\mathbf{5}$ This shows the number of respondents that attended their primary care provider with symptoms from the NET

\begin{tabular}{|c|c|c|c|c|c|c|c|}
\hline \multirow[b]{2}{*}{ Site of NET } & \multirow[b]{2}{*}{ Respondents } & \multicolumn{3}{|l|}{ Primary Care } & \multicolumn{3}{|l|}{ Secondary Care } \\
\hline & & $\%$ seen by GP & $\begin{array}{l}\text { Mean No. times } \\
\text { seen by GP }\end{array}$ & $\begin{array}{l}\text { Mean time GP } \\
\text { investigated (months) }\end{array}$ & $\%$ seen in clinic & $\begin{array}{l}\text { Mean No. times } \\
\text { seen in clinic }\end{array}$ & $\begin{array}{l}\text { Mean time clinic } \\
\text { investigated (months) }\end{array}$ \\
\hline Lung & 51 & $73 \%$ & 14 & 44 & $55 \%$ & 3 & 4 \\
\hline Pancreas & 52 & $73 \%$ & 8 & 33 & $50 \%$ & 4 & 21 \\
\hline Small Bowel & 86 & $86 \%$ & 10 & 40 & $62 \%$ & 3 & 11 \\
\hline All/(mean) & 257 & $(80 \%)$ & $(11)$ & (37) & $(58 \%)$ & (3) & $(17)$ \\
\hline
\end{tabular}

The number of visits related to the GP and also secondary care if referred via their GP. The final column encompasses all respondents that completed this part of the questionnaire and not separated by tumour site

care interaction was via an unplanned emergency admission from A\&E (see Table 7). Again there was no marked difference in the routes that sbNET and pNET respondents first interacted with secondary care. $43 \%$ of pNET and sbNET respondents reported that they were investigated in gastroenterology clinics prior to diagnosis with others mainly investigated in surgical or oncology clinics. Respondents reported that they were investigated in clinic for a mean period of 17 months over a mean of 3 occasions. There is likely to be overlap in primary and secondary care management (37 and 17 months respectively) given respondents also reported being symptomatic for similar period of time (mean 53.8 months) and the likelihood of a staggered presentation to first access healthcare. However, it was not possible to quantify the overlap in primary and secondary care given the questionnaire design.

\section{Discussion}

The survey is one of the most detailed in terms of exploring symptoms and access to healthcare prior to diagnosis of patients with NETs. The majority of respondents had, as expected, small bowel, pancreatic or lung NETs. However, responses were received from respondents with tumours arising from a number of different primary sites. The mean age of the respondents to the survey was somewhat younger than the mean age of diagnosis of NET. This is in part related to the inherent

Table 6 This table lists the commonly made initial diagnosis in primary and secondary care when respondents attended with the symptoms related to their NET

\begin{tabular}{|c|c|c|c|c|c|c|}
\hline \multirow[t]{2}{*}{ Potential cause } & \multicolumn{3}{|c|}{ Primary Care } & \multicolumn{3}{|c|}{ Secondary Care } \\
\hline & Pancreas & Small Bowel & Grand Total & Pancreas & Small Bowel & Grand Total \\
\hline IBS & $16 \%$ & $29 \%$ & $24 \%$ & $5 \%$ & $12 \%$ & $9 \%$ \\
\hline Dyspepsia & $9 \%$ & $16 \%$ & $13 \%$ & $3 \%$ & $3 \%$ & $3 \%$ \\
\hline Depression & $5 \%$ & $3 \%$ & $4 \%$ & $2 \%$ & $1 \%$ & $1 \%$ \\
\hline UTI & $5 \%$ & $3 \%$ & $4 \%$ & $0 \%$ & $0 \%$ & $0 \%$ \\
\hline Constipation & $3 \%$ & $5 \%$ & $4 \%$ & $2 \%$ & $1 \%$ & $1 \%$ \\
\hline Gall Stones & $8 \%$ & $12 \%$ & $10 \%$ & $3 \%$ & $5 \%$ & $4 \%$ \\
\hline Menopause & $2 \%$ & $11 \%$ & $7 \%$ & $0 \%$ & $3 \%$ & $2 \%$ \\
\hline Chest infection & $2 \%$ & $2 \%$ & $2 \%$ & $0 \%$ & $0 \%$ & $0 \%$ \\
\hline Haemorrhoids & $0 \%$ & $0 \%$ & $0 \%$ & $0 \%$ & $0 \%$ & $0 \%$ \\
\hline Kidney stones & $5 \%$ & $3 \%$ & $4 \%$ & $3 \%$ & $1 \%$ & $2 \%$ \\
\hline Anaemia & $5 \%$ & $5 \%$ & $5 \%$ & $2 \%$ & $0 \%$ & $1 \%$ \\
\hline Crohn's & $0 \%$ & $2 \%$ & $1 \%$ & $2 \%$ & $1 \%$ & $1 \%$ \\
\hline NET & $0 \%$ & $2 \%$ & $1 \%$ & $20 \%$ & $22 \%$ & $21 \%$ \\
\hline Ulcerative colitis & $5 \%$ & $4 \%$ & $4 \%$ & $0 \%$ & $1 \%$ & $1 \%$ \\
\hline Cancer & $3 \%$ & $4 \%$ & $4 \%$ & $17 \%$ & $14 \%$ & $15 \%$ \\
\hline They were not sure & $9 \%$ & $19 \%$ & $15 \%$ & $6 \%$ & $15 \%$ & $12 \%$ \\
\hline Not sure & $8 \%$ & $8 \%$ & $8 \%$ & $6 \%$ & $5 \%$ & $6 \%$ \\
\hline Other & $22 \%$ & $25 \%$ & $24 \%$ & $23 \%$ & $23 \%$ & $23 \%$ \\
\hline Respondents & 64 & 99 & 163 & 64 & 99 & 163 \\
\hline
\end{tabular}

The percentage is derived from the initial diagnosis given to patients by the total number of patients. For example 10 of 64 patients (16\%) with pNETs were initially given a diagnosis of IBS. Abbreviations: IBS irritable bowel syndrome, UTI urinary tract infection, NET neuroendocrine tumour 
Table 7 This table demonstrates the number of patients presenting to A\&E either directly or following referral via GP

\begin{tabular}{lllll}
\hline Site of NET & $\begin{array}{l}\text { Emergency } \\
\text { admission } \\
\text { from A\&E }\end{array}$ & $\begin{array}{l}\text { Via a GP referral } \\
\text { as an emergency } \\
\text { admission to the } \\
\text { local hospital }\end{array}$ & $\begin{array}{l}\text { Via a GP } \\
\text { referral to a } \\
\text { local hospital }\end{array}$ & Numbers \\
\hline Appendix & $30 \%$ & $40 \%$ & $30 \%$ & 10 \\
Lung & $30 \%$ & $18 \%$ & $52 \%$ & 33 \\
Not sure & $50 \%$ & $20 \%$ & $30 \%$ & 10 \\
Pancreas & $40 \%$ & $4 \%$ & $56 \%$ & 45 \\
Rectal & $0 \%$ & $0 \%$ & $100 \%$ & 3 \\
Renal/Kidney & $0 \%$ & $0 \%$ & $100 \%$ & 1 \\
Small Bowel & $32 \%$ & $5 \%$ & $63 \%$ & 76 \\
Stomach/ & $22 \%$ & $11 \%$ & $67 \%$ & 9 \\
gastric & & $13 \%$ & $70 \%$ & 23 \\
Unknown & $17 \%$ & $10 \%$ & $58 \%$ & $100 \%$ \\
Primary & & 22 & 122 & 210 \\
Overall \% & $31 \%$ & $10 \%$ & & \\
Numbers & 66 & 22 & &
\end{tabular}

In addition, \% of patients that are referred to secondary care by primary tumour site

bias in asking patients with NETs to only complete an online survey.

The time from first symptom to diagnosis was 53.8 months, which is a very long time especially when considering the number of respondents that regarded their primary symptom as being severe or very severe in nature. A significant delay is likely to be occurring due to incorrect initial diagnosis. Commonly, functional bowel disorders were the initial diagnosis in a number of cases.

There is a scarcity of data on delays and routes to diagnosis for patients with neuroendocrine tumours. In 2014, the International Neuroendocrine Cancer Alliance (INCA) commissioned a general global survey of patients with NETS. Part of this questionnaire addressed routes and time to diagnosis. Interestingly, they reported a mean patient reported time from first symptom to diagnosis of 52 months; with $29 \%$ of patients requiring greater than 5 years for a NET diagnosis [6]. A subgroup of these respondents from USA was further analysed and this confirmed that patient reported time from first symptom to onset of clinical diagnosis of 59 months [10]. This data is similar to what we have demonstrated in this study and indicates that is different models of healthcare delivery there appear to be a similar delay in diagnosis.

Seventy-four (24\%) respondents had lost greater than $4.5 \mathrm{~kg}$ in weight and this should lead to investigation as to the cause of this weight loss. Furthermore, over half of respondents were aged over 50 years old and had red flag symptoms at the time of presentation including weight loss and reduced appetite. Whilst a fraction of patients met the criteria for conditions such as irritable bowel syndrome, the majority has an age of onset of symptoms over 50 and other alarm symptoms that should warrant investigation prior to assuming a diagnosis of a functional syndrome such as dyspepsia.

The survey has clearly demonstrated that the majority of respondents with NETs do not present with typical symptoms. For example, carcinoid syndrome symptoms were not being floridly reported by those with small bowel NETs. Therefore, the diagnosis of NETs will require investigation of vague nonspecific often abdominal or gastrointestinal related symptoms. Therefore, the role of cross sectional imaging is important to help expedite this diagnosis.

Reduced health-seeking behaviour in UK patients has been highlighted as a factor in later stage disease at presentation and consequent worse outcomes than other developed countries [11]. The public health messaging around cancer symptomatology and the introduction of screening programmes, such as the bowel cancer screening programme, can help improve outcomes but have no clear secondary benefit for other malignancies like NET [12]. Patients with symptoms like diarrhoea and pain may be investigated with simple and accessible diagnostics, such as abdominal ultrasound, endoscopy and blood testing, that maybe falsely reassuring given the low sensitivity for early NET disease. Cross-sectional modalities like CT and/or MRI may reveal earlier stage disease, particularly when used in patients who are 50 years old with new symptoms.

This survey does clearly demonstrate that there is no reduced health seeking behavior from these respondents with $80 \%$ of respondents visiting their GP on average 11 times related to the symptoms from NET prior to diagnosis. This suggests that it is not healthcare avoidance by the public, but lack of onward referral or appropriate investigations in the primary and secondary care setting that seems to be contributing to the delay in diagnosis.

The survey was limited by its retrospective nature and inclusion of all historical NET patients. There was an average of four years from diagnosis to completing the survey that could significantly bias a patient's recall. The patients' perception of their initial symptoms being related to the tumour needs to be interpreted with caution in some cases. For example, $25 \%$ of participants with rectal NETs reported cough as their first symptom, which seems unlikely. In most cases however, the primary symptoms would fit with the underlying type of NET. For example, respondents with small bowel NETs described pain (36\%), flushing (26\%) and diarrhoea (24\%) as the most common first symptoms. However, events and symptomatology that occurred well after diagnosis, including post-surgical symptoms, could easily be mixed with those occurring prior to diagnosis. The survey was predominantly accessed via the NET patient 
foundation's digital promotional channels that could represent a self-selecting informed and proactive cohort of NET patients. The responses may be not representative of the majority of NET patients in the UK who may have different symptom, disease and healthcare experiences. The mean age at diagnosis in the cohort that responded to the study is younger than would be expected based on epidemiological data. Therefore, suggesting a selective group that use online platforms or have social media accounts.

\section{Conclusion}

In summary, this survey demonstrates a mean time of 53.8 months from onset of symptoms to diagnosis. The primary symptoms from respondents appear linked to the primary site of the tumour and associated weight loss is a common finding. Respondents are seeking healthcare but are often misdiagnosed with functional gastrointestinal disorders. Further education regarding investigation of malignancy in patients over 50 and greater use of cross sectional imaging for patients with alarm symptoms over 50 may help shorten the time to diagnosis of NETs.

\section{Acknowledgements}

Not applicable.

\section{Funding}

No external funding to declare.

\section{Availability of data and materials}

The datasets used and/or analysed during the current study are available from the corresponding author on reasonable request

\section{Authors' contributions}

RB: designed, collected, analysed and wrote manuscript; CB and JKR: designed, reviewed and analysed the data; MS: designed and analysed the data. RS: designed, analysed and wrote the manuscript. All authors read and approved the final manuscript.

\section{Authors' information}

JKR: Professor of gastroenterology; ENETS executive committee member; Chairman of UKINETS. RS: Consultant gastroenterologist and member of UKINETS.

\section{Ethics approval and consent to participate}

Not applicable. This was an online anonymous survey and following completing the HRA decision aids tool an online form, it confirmed that NHS REC approval was not required.

\section{Consent for publication}

Not applicable

\section{Competing interests}

The authors declare that they have no competing interests.

\section{Publisher's Note}

Springer Nature remains neutral with regard to jurisdictional claims in published maps and institutional affiliations.

\section{Author details}

'Department of Liver Sciences, Division of Transplantation Immunology \& Mucosal Biology, King's College London, London, UK. ${ }^{2}$ Neuroendocrine Tumour Patient Foundation, Leamington Spa, UK. ${ }^{3}$ ENETS Centre of Excellence, Neuroendocrine Tumour Unit, Kings College Hospital, London,
UK. ${ }^{4}$ Department of Gastroenterology, Kings College Hospital, London SE5 9RS, UK.

Received: 15 May 2018 Accepted: 7 November 2018

Published online: 16 November 2018

\section{References}

1. Yao JC, et al. One hundred years after 'carcinoid': epidemiology of and prognostic factors for neuroendocrine tumors in 35,825 cases in the United States. J Clin Oncol. 2008;26(18):3063-72.

2. Topping M, Gray D, Friend E, Davies A, Ramage J. A systematic review of symptoms and quality of life issues in pancreatic neuroendocrine Tumours. Neuroendocrinology. 2017;105:320-30.

3. Basuroy R, Srirajaskanthan R, Ramage JK. Neuroendocrine Tumors. Gastroenterol Clin N Am. 2016:45(3):487-507.

4. Modlin IM, et al. Gastroenteropancreatic neuroendocrine tumours. Lancet Oncol. 2008;9(1):61-72.

5. Ramage JK, et al. Guidelines for the management of gastroenteropancreatic neuroendocrine (including carcinoid) tumours (NETs). Gut. 2012;61(1):6-32.

6. Singh $\mathrm{S}$, et al. Patient-reported burden of a neuroendocrine tumor (NET) diagnosis: results from the first global survey of patients with NETs. J Glob Oncol. 2016:3(1):43-53.

7. Pavel M, Kolarova T, Goldstein G, Leyden J, Sissons M. Patient-reported time to diagnosis of neuroendocrine tumors (NETs) in Europe: results from the first global NET patient survey: a collaboration between the international neuroendocrine Cancer Alliance (INCA) and Novartis. Endocr Abstr. 2015.

8. Wilson HM. Chronic subacute bowel obstruction caused by carcinoid tumour misdiagnosed as irritable bowel syndrome: a case report. Cases J. 2009;2(1):78.

9. Feinberg Y, Law C, Singh S, Wright FC. Patient experiences of having a neuroendocrine tumour: a qualitative study. Eur J Oncol Nurs. 2013;17(5): 541-5.

10. Wolin EM, Leyden J, Goldstein G, Kolarova T, Hollander R, Warner RRP. Patient-reported experience of diagnosis, management, and burden of neuroendocrine tumors: results from a large patient survey in the United States. Pancreas. 2017;46(5):639-47.

11. McCutchan G, Wood F, Smits S, Edwards A, Brain K. Barriers to cancer symptom presentation among people from low socioeconomic groups: a qualitative study. BMC Public Health. 2016;16(1):1052.

12. Hamashima C, Shabana M, Okada K, Okamoto M, Osaki Y. Mortality reduction from gastric cancer by endoscopic and radiographic screening. Cancer Sci. 2015;106(12):1744-9.

Ready to submit your research? Choose BMC and benefit from:

- fast, convenient online submission

- thorough peer review by experienced researchers in your field

- rapid publication on acceptance

- support for research data, including large and complex data types

- gold Open Access which fosters wider collaboration and increased citations

- maximum visibility for your research: over $100 \mathrm{M}$ website views per year

At BMC, research is always in progress.

Learn more biomedcentral.com/submissions 